\title{
Distribution Differences of Vesicular Glutamate Transporters in Mammalian, Reptilian, and Avian Brain
}

\author{
Sonjoy Sarkar ${ }^{1,2 *}$ \\ ${ }^{1}$ Department of Basic Veterinary Science, Gifu University, Japan \\ ${ }^{2}$ Department of Anatomy and Histology, Sylhet Agricultural University, Bangladesh
}

Submission: March 07, 2019; Published: March 19, 2019

*Corresponding author: Sonjoy Sarkar, Department of Basic Veterinary Science, United Graduate School of Veterinary Sciences, Gifu University, Yanagido 1-1, Gifu 501-1193, Japan

\begin{abstract}
The activity of the neurons of central nervous system is controlled by glutamatergic neurotransmission and glutamate plays the crucial role by acting as excitatory neurotransmitter. After synthesis in the neuronal cell bodies, glutamate is transported in the presynaptic vesicle of the presynaptic neurons by transporter protein family known as Vesicular Glutamate Transporters (VGLUTs). This protein family is also responsible for doing normal brain functions such as- learning and memory. Three and two isoforms of VGLUTs have identified in mammalian and avian brain, respectively. Recently, three types of VGLUTs identified in reptilian brain, but the difference between their distribution patterns is still unclear. Therefore, this mini-review summarizes the updated knowledge about the distribution patterns of different isoforms of VGLUTs in mammalian, reptilian, and avian brain with their concrete comparison.
\end{abstract}

Keywords: vesicular glutamate transporter; glutamatergic neurons; neurotransmission; mRNA; brain

\section{Introduction}

Glutamate is an amino acid present in all types of cells and associated with many cellular functions [1]. In the brain, glutamate acts as the main excitatory neurotransmitter and plays important roles in many neuronal processes such as synaptic transmission and neuronal plasticity and also involved in many neurological and psychiatric disorders [2]. Vesicular Glutamate Transporters (VGLUTs) are responsible for uploading glutamate into the synaptic vesicles at the presynaptic terminals to release [3]. These glutamate transporters were previously recognized in mammalian and avian brains and very recently in reptilian brain and marked as a major anatomical and functional marker of glutamatergic transmission [1,4-10]. Three isoforms of VGLUTs (VGLUT1-3) have been identified in mammals and the distribution of their mRNA and protein has been investigated thoroughly in the brain $[4,5,11,12]$. VGLUT1 and VGLUT2 are considered specific biomarkers of glutamatergic neurons, and they show a complementary distribution pattern in the mammalian brain $[4,13]$. VGLUT3 is distributed sparsely and is found in a subpopulation of non-glutamatergic neurons that synthesize other neurotransmitters, such as acetylcholine, serotonin, and $\gamma$-aminobutyric acid (GABA) in the brain $[12,13]$.

On the other hand, two isoforms of VGLUTs (VGLUT2-3) have been identified in birds and their mRNA distributions have been studied in the pigeon and zebra finch brain with widely expressed VGLUT2 and VGLUT3 only in caudal linear nucleus $[8,9,14]$. Recently, three isoforms of VGLUTs have also identified in the turtle brain as reptilian model [10]. For the first time VGLUT1-3 mRNAs distribution patterns identified in any reptilian brain in the study of Sarkar \& Atoji [10]. Therefore, like as the mammalian and avian brains, these transporters may play some fundamentals roles in reptilian brain also. Previously, multiple VGLUTs isoforms have been identified in many other lower organisms like Drosophila, zebrafish, and frog [15-17]. Taking together, expression patterns of VGLUTs mRNA suggests that they conserve with evolution. However, in the higher brain their differences in distribution patterns have not yet been resolute solely. Therefore, the aim of this study is to identify the differences between the expression patterns of different isoforms of VGLUTs in mammalian, reptilian, and avian brain.

\section{Distribution patterns of three VGLUTs isoform in mammalian brain}

\section{VGLUT1}

Among three isoforms, VGLUT1 and 2 showed complementary distribution pattern in mammalian brain (Table 1). VGLUT1 is generally abundant in telencephalic region. Except lower 
expression in neocortical layer 4, strong expression is identified in remaining layers [18]. VGLUT1 is also localized in some other nuclei of the telencephalon e.g. entorhinal and piriform cortex, hippocampus, amygdala, and subiculum as well as in the olfactory tubercle $[2,18,19]$. A very few number of diencephalic nuclei are VGLUT1 positive. The granule cells of the cerebellum but not the deep cerebellar nuclei are glutamatergic in nature by showing VGLUT1 positivity [20]. Some rhomb encephalic nuclei are also showed differential expression pattern.

\section{VGLUT2}

In comparison with VGLUT1, VGLUT2 expressed strongly in the diencephalic nuclei (Table 1). In different layers of neocortex, VGLUT2 is abundant in layer 4 and co-expression with VGLUT1 in some other telencephalic nuclei has also been previously identified [20]. The deep cerebellar nuclei along with a considerable numbers of brainstem nuclei such as- rostrocaudal part of the periaqueductal gray, latero-dorsal tegmental, lateral and medial parabrachial, pedunculo-pontine, KöllikerFuse, solitary tract, and ventrolateral medulla have identified as glutamatergic on the basis of VGLUT2 expression [21].

\section{VGLUT3}

The distribution pattern of the third VGLUT is little bit unexpected (Table 1). In contrast with VGLUT1 and 2, VGLUT3 is discretely distributed throughout the brain and surprisingly co-localized with other neurotransmitters e.g GABAergic, serotonergic, and cholinergic markers [19]. Very limited number of the glutamatergic neurons of the multiple brain regions, such as- neocortex, hippocampus, olfactory bulb, hypothalamus, substantia nigra, and raphe nuclei are VGLUT3 positive [2]. The co-localization nature of the VGLUT3 with other types of neurotransmitter suggests that co-localizing neurons are capable of co-release of both glutamate and other classical neurotransmitters $[7,11,12,19]$.

Table 1: Comparison of distribution summary of VGLUTs isoform in mammalian, reptilian, and avian brain.

\begin{tabular}{|c|c|c|c|c|c|c|c|c|}
\hline \multirow{2}{*}{ Regions } & \multicolumn{3}{|c|}{ Mammals } & \multicolumn{3}{|c|}{ Reptiles } & \multicolumn{2}{|c|}{ Birds } \\
\hline & VGLUT1 & VGLUT2 & VGLUT3 & VGLUT1 & VGLUT2 & VGLUT3 & VGLUT2 & VGLUT3 \\
\hline \multicolumn{9}{|c|}{ Telencephalon } \\
\hline Pallium & +++ & ++ & + & +++ & ++ & - & +++ & - \\
\hline Sub pallium & - & + & - & - & + & - & + & - \\
\hline \multicolumn{9}{|l|}{ Diencephalon } \\
\hline Thalamus & ++ & +++ & - & - & +++ & - & +++ & - \\
\hline Hypothalamus & ++ & +++ & - & - & +++ & - & +++ & - \\
\hline Mesencephalon & + & ++ & - & + & + & + & ++ & - \\
\hline \multicolumn{9}{|l|}{ Rhombencephalon } \\
\hline Cerebellar granular layer & +++ & - & - & +++ & - & - & +++ & - \\
\hline Cerebellar \& other brainstem nuclei & + & +++ & ++ & + & +++ & ++ & +++ & ++ \\
\hline
\end{tabular}

+++ = intense expression, $++=$ moderate expression, $+=$ weak expression, $-=$ no expression.

\section{Distribution patterns of three VGLUTs isoform in reptilian brain}

\section{VGLUT1}

Like as the mammalian brain, reptilian VGLUT1 and 2 also distributed in a complimentary manner but the expression of the VGLUT1 is stronger than VGLUT2 in complementary sites (Table 1). The telencephalic pallium along with lateral and medial part of the amygdaloid nuclei, lateral olfactory tract nucleus, and mitral cell layer of the olfactory bulb are VGLUT1 positive [10]. Sub pallium part and the central amygdaloid nucleus is not VGLUT1 positive. Cerebellar granular layer and very few nuclei of the brainstem express the signal of VGLUT1.

\section{VGLUT2}

Telencephalic VGLUT1 positive nuclei are also positive for VGLUT2, but the expression is weaker than the VGLUT1 (Table 1). Sub pallial medial septal nucleus is showed glutamatergic nature based on the VGLUT2 expression [10]. VGLUT2 is abundant in the diencephalic nuclei which is the persistent result like mammalian brain. A negligible number of nuclei of the mesencephalon but a considerable number of the rhombencephalic nuclei are glutamatergic in nature according to the expression of the VGLUT2 mRNA [10].

\section{VGLUT3}

Sarkar \& Atoji [10] found an astonishing expression pattern of the VGLUT3 in turtle brain (Table 1). Telencephalon and diencephalon is devoid of expression, but expression found only in the parvocellular part of isthmic nucleus of mesencephalon and brainstem cochlear and raphe nuclei [10].

\section{Distribution patterns of two VGLUTs isoform in avian brain}

\section{VGLUT2}

VGLUT1 have not been identified in the avian brain yet. VGLUT2 showed corresponding expression pattern with that of the VGLUT1 and 2 of the mammalian brain $[8,14]$. In the avian 


\section{Open Access Journal of Neurology \& Neurosurgery}

brain VGLUT2 both in the telencephalic and the diencephalic nuclei along with some mesencephalic and lower brainstem nuclei (Table 1).

\section{VGLUT3}

VGLUT3 only expressed in the caudal linear nucleus of the brainstem of pigeon [9]. The caudal linear nucleus is serotonergic in nature which suggests that glutamate and serotonin are colocalizing in that nucleus.

\section{Concluding remarks}

Expression patterns of VGLUTs mRNA in mammalian, reptilian, and avian brain is somewhat similar with a little variation. It means that these transporters may play some fundamentals role in brain functions which may conserve with evolution, but physiological future research is needed to identify the accurate function in the reptilian brain though it seems that they may play similar function like mammalian and avian brain.

\section{References}

1. Vigneault É, Poirel O, Riad M, Prud homme J, Dumas S, et al. (2015) Distribution of vesicular glutamate transporters in the human brain. Front Neuroanat 9: 23

2. Liguz-Lecznar M, Skangiel-Kramska J (2007) Vesicular glutamate transporters (VGLUTs): The three musketeers of glutamatergic system. Acta Neurobiol Exp 67(3): 207-218.

3. El Mestikawy S, Wallen-Mackenzie A, Fortin GM, Descarries L, Trudeau LE (2011) From glutamate co-release to vesicular synergy: vesicular glutamate transporters. Nat Rev Neurosci 12(4): 204-216.

4. Ni B, Rosteck PR Jr, Nadi NS, Paul SM (1994) Cloning and expression of a cDNA encoding a brain-specific $\mathrm{Na}^{+}$-dependent inorganic phosphate cotransporter. Proc Natl Acad Sci USA 91(12): 5607-5611.

5. Aihara Y, Mashima H, Onda H, Hisano S, Kasuya H, et al. (2000) Molecular cloning of a novel brain-type $\mathrm{Na}^{(+)}$-dependent inorganic phosphate cotransporter. J Neurochem 74(6): 2622-2625.

6. Takamori S, Rhee JS, Rosenmund C, Jahn R (2000) Identification of a vesicular glutamate transporter that defines a glutamatergic phenotype in neurons. Nature 407(6801): 189-194.

7. Schafer MK, Varoqui H, Defamie N, Weihe E, Erickson JD (2002) Molecular cloning and functional identification of mouse vesicular glutamate transporter 3 and its expression in subsets of novel excitatory neurons. J Biol Chem 277(52): 50734-50748.

8. Islam MR, Atoji Y (2008) Distribution of vesicular glutamate transporter 2 and glutamate receptor 1 mRNA in the central nervous system of the pigeon (Columba livia). J Comp Neurol 11(5): 658-677.
9. Karim MR, Saito S, Atoji Y (2014) Distribution of vesicular glutamate transporter 2 in the auditory and song control brain regions in the adult zebra finch (Taeniopygia guttata). J Comp Neurol 522(9): 21292151.

10. Sarkar S, Atoji Y (2018) Distribution of vesicular glutamate transporters in the brain of the turtle (Pseudemys scripta elegans). J Comp Neurol 526(10): 1690-1702.

11. Fremeau RT Jr, Troyer MD, Pahner I, Nygaard GO, Tran CH, et al. (2001) The expression of vesicular glutamate transporters defines two classes of excitatory synapse. Neuron 31(2): 247-260.

12. Herzog E, Bellenchi GC, Gras C, Bernard V, Ravassard P, et al. (2001) The existence of a second vesicular glutamate transporter specifies subpopulations of glutamatergic neurons. J Neurosci 21(22): RC181.

13. Hisano S, Hoshi K, Ikeda Y, Maruyama D, Kanemoto M, et al. (2000) Regional expression of a gene encoding a neuron specific $\mathrm{Na}^{+}-$ dependent inorganic phosphate cotransporter (DNPI) in the rat forebrain. Mol Brain Res 83(1-2): 34-43.

14. Atoji Y, Karim MR (2014) Expression of vesicular glutamate transporter 3 mRNA in the brain and retina of the pigeon. J Chem Neuroanat 61-62: 124-131.

15. Gleason KK, Dondeti VR, Hsia HL, Cochran ER, Gumulak-Smith J, et al. (2003) The vesicular glutamate transporter 1 (xVGlut1) is expressed in discrete regions of the developing Xenopus laevis nervous system. Gene Expr Patterns 3(4): 503-507.

16. Daniels RW, Collins CA, Gelfand MV, Dant J, Brooks ES, et al. (2004) Increased expression of the Drosophila vesicular glutamate transporter leads to excess glutamate release and a compensatory decrease in quantal content. J Neurosci 24(46): 10466-10474.

17. Higashijima S, Mandel G, Fetcho JR (2004) Distribution of prospective glutamatergic, glycinergic, and GABAergic neurons in embryonic and larval zebrafish. J Comp Neurol 480(1): 1-18.

18. Fremeau RT Jr, Voglmaier S, Seal RP, Edwards RH (2004) VGLUTs define subsets of excitatory neurons and suggest novel roles for glutamate. Trend Neurosci 27(2): 98-103.

19. Takamori (2006) VGLUTs: 'Exciting' times for glutamatergic research? Neurosci Res 55(4): 343-351.

20. Danik M, Cassoly E, Manseau F, Sotty F, Mouginot D, et al. (2005) Frequent coexpression of the vesicular glutamate transporter 1 and 2 genes, as well as coexpression with genes for choline acetyltransferase or glutamic acid decarboxylase in neurons of rat brain. J Neurosci Res 81(4): 506-521.

21.Ziegler DR, Edwards MR, Ulrich-Lai YM, Herman JP, Cullinan WE (2012) Brainstem Origins of Glutamatergic Innervation of the Rat Hypothalamic Paraventricular Nucleus. J Comp Neurol 520(11): 23692394. 
This work is licensed under Creative Commons Attribution 4.0 Licens

DOI: 10.19080/OAJNN.2019.10.555786

\section{Your next submission with Juniper Publishers will reach you the below assets}

- Quality Editorial service

- Swift Peer Review

- Reprints availability

- E-prints Service

- Manuscript Podcast for convenient understanding

- Global attainment for your research

- Manuscript accessibility in different formats

( Pdf, E-pub, Full Text, Audio)

- Unceasing customer service

Track the below URL for one-step submission https://juniperpublishers.com/online-submission.php 